\title{
DIFERENÇAS ENTRE AS PERSPECTIVAS DE EDUCAÇÃO INTEGRAL EM ANÍSIO TEIXEIRA E NO PROGRAMA MAIS EDUCAÇÃO
}

\author{
Bruno Adriano Rodrigues da Silva ${ }^{1}$
}

\section{RESUMO}

As discussões recentes sobre o tema da educação integral em tempo integral no campo da educação apresentam a predominância da perspectiva do programa Mais Educação que é uma estratégia do Ministério da Educação visando à ampliação da jornada escolar nas escolas públicas brasileiras, conforme prevê a legislação. Esse programa justifica a sua perspectiva fazendo referência ao trabalho desenvolvido pelo educador Anísio Teixeira, no entanto acreditamos que essa perspectiva de educação integral do Mais Educação realiza uma leitura equivocada desse trabalho, porque desconsidera os elementos contextuais pertinentes à produção desse educador. Essa será a hipótese que conduzirá o trabalho, cujo objetivo é identificar e demonstrar as diferenças entre a perspectiva do programa Mais Educação e do educador Anísio Teixeira, colocando em relevo as suas contribuições para o tema da educação integral em particular, e, em geral, para a oferta do direito à educação que se pretenda universal, isto é, para todos.

Palavras-chave: educação integral em tempo integral; programa Mais Educação; Anísio Teixeira; direito à educação

\section{DIFFERENCES BETWEEN THE PERSPECTIVE FOR INTEGRAL EDUCATION IN ANÍSIO TEIXEIRA AND MAIS EDUCAÇÃO PROGRAM}

\begin{abstract}
The recent discussions about full-time education theme on the education field shows the predominance of perspective of the Mais Educação program, that is a strategy of Ministerio da Educação aiming to extend journey in Brazilian public schools, as the law provides. This program justifies its perspective by reference to the work of the educator Anísio Teixeira, however we believe this perspective of full-time education in the Mais Educação program performs a misreading of this work, because disregards contextual elements in production of this educator. This is the hypothesis will lead the work that follows, whose goal is to identify and demonstrate the differences between the perspective of Mais Educação program and the educator AnisioTeixeira, putting emphasis on their contributions to the theme of full-time education in particular and for offer of the right to education that is to be universal, namely, for all.
\end{abstract}

Key-words: full-time education; Mais Educação program; Anísio Teixeira; right to education

\section{Introdução}

As discussões recentes sobre o tema da educação integral em tempo integral no campo da educação apresentam a predominância da perspectiva do programa Mais Educação, que é uma estratégia do Ministério da Educação visando à progressiva 
ampliação da jornada escolar nas escolas públicas brasileiras, conforme a previsão do artigo 34 da lei de Diretrizes e Bases da Educacional (Lei 9.304/1996). Esse programa justifica a sua perspectiva fazendo referência ao trabalho desenvolvido pelo educador Anísio Teixeira. Acreditamos que essa perspectiva de educação integral do programa Mais Educação realiza uma leitura equivocada desse trabalho, na medida em que desconsidera os elementos contextuais pertinentes à produção desse educador, quais sejam: igualdade de oportunidades; a educação compreendida como um sistema amplo e articulado; a ampliação das atividades escolares; bem como a participação comunitária.

Essa será a hipótese que conduzirá o trabalho, cujo objetivo é identificar e demonstrar as diferenças entre a perspectiva do programa Mais Educação e do educador Anísio Teixeira, colocando em relevo as suas contribuições para o tema da educação integral em particular, e, em geral, para a oferta do direito à educação que se pretenda universal, isto é, para todos.

Utilizamos como referência a contribuição de estudos sobre o tema da educação integral em tempo integral que entendem que a perspectiva do programa Mais Educação é contrária a do educador Anísio Teixeira por não apresentar aspectos favoráveis à universalização da educação. (COELHO, 2009; CAVALIERE, 2011; SILVA, 2013).

Também utilizamos como referência as contribuições de Anísio Teixeira publicadas entre os anos de 1927 e 19362: "Aspectos Americanos de Educação e Anotações de Viagem aos Estados Unidos em 1927”; Pequena Introdução à Filosofia da Educação: a Escola Progressiva ou a Transformação da Escola; Em Marcha para a Democracia: à Margem dos Estados Unidos; Educação para a Democracia: introdução à administração Educacional.

Diante desse quadro, organizamos o trabalho do seguinte modo: i) analisamos a perspectiva de educação integral do programa Mais Educação; ii) analisamos a perspectiva de educação integral do educador Anísio Teixeira; iii)por último, na conclusão deste artigo, apresentamos as diferenças entre a perspectiva do programa Mais Educação e a perspectiva de Anísio Teixeira no tocante ao foco deste estudo - a educação integral em tempo integral.

\subsection{A perspectiva de educação integral do programa Mais Educação.}

Podemos identificar na história da educação brasileira três matrizes ideológicas que engendram perspectivas de educação integral: as conservadoras, especialmente aquelas alinhadas a um entendimento totalitário da educação, caso da perspectiva da Ação Integralista Brasileira e das perspectivas religiosas, por exemplo; as liberais, que se filiavam a uma perspectiva desenvolvimentista voltada para o progresso, em geral, defensora da ideia do universalismo na educação, caso dos pioneiros da Educação Nova no Brasil e de toda a tradição decorrente deste movimento do qual Anísio Teixeira foi signatário; e as socialistas que baseavam suas experiências no entendimento de que educação integral deveria ser vista como um meio de emancipação social, um instrumento de construção de igualdades e não o contrário, caso dos anarquistas e dos marxistas. (COELHO, 2009).

Em nossa opinião, o programa Mais Educação não pode ser vinculado a nenhuma dessas perspectivas, apesar dele fazer uso da perspectiva de Anísio Teixeira - que é liberal, segundo a autora citada no parágrafo acima - como referencia, conforme consta em trabalhos acadêmicos elaborados pelos executores do programa que, inclusive, defendem a instituição escolar como uma problemática "essencial" em relação ao desenvolvimento social brasileiro: 
Dia a dia, toma a nação maior e mais intensa consciência de si mesma, de seus problemas, de suas contradições, de suas desigualdades, de seus diferentes níveis e modos de viver, de suas distâncias físicas e psicológicas, de sua pobreza e de sua riqueza, do seu progresso e do seu atraso, e, reunindo todas as suas forças, prepara-se para uma nova integração, em um grande esforço de reconstrução e desenvolvimento. Nesse processo de reconstrução, nenhum problema é mais essencial que o da escola, pois por ela é que se efetivará o novo senso de consciência nacional e se afirmará a possibilidade de se fazer permanente e progressiva a grande mobilização do esforço brasileiro (TEIXEIRA apud MOLL, 2012).

Trabalhamos com esse entendimento, sobretudo porque o programa Mais Educação não apresenta a universalização da educação como um traço essencial em seus desdobramentos, apesar de fazer menção a isso em seus documentos oficiais. Ele consiste, apenas, em uma indução, isto é, tanto o Ministério da Educação, quanto os formuladores do programa, por meio de documentos oficiais e publicações acadêmicas afirmam que esta ação não se configura como uma política pública - devido as suas características normativas - e sim como um "(...) instrumento, por excelência, para a oferta dos serviços educacionais" com vistas a que os municípios e os estados da federação desenvolvam suas próprias políticas públicas voltadas para a ampliação da jornada escolar, por meio da educação integral (BRASIL, 2009a; MOLL, 2012).

Ainda de acordo com os documentos oficiais, essas políticas públicas desenvolvidas em estados e municípios, para integrarem essa estratégia indutiva apresentada pelo MEC, devem estar de acordo com as suas diretrizes, quais sejam: ampliar o tempo diário de permanência dos alunos nas escolas para sete horas ou mais; ser direcionadas aos alunos que possuem baixo rendimento escolar ou se encontram em situação de vulnerabilidade social; serem realizadas com base no trabalho voluntário de indivíduos preferencialmente oriundos das comunidades que cercam as escolas, e por meio de oficinas organizadas em macro campos do conhecimento (esporte, arte e cultura, reforço escolar, saúde, entre outros), realizadas dentro ou fora do espaço escolar ${ }^{3}$ no contraturno (BRASIL, 2010).

Segundo formulações acadêmicas que defendem essa estratégia indutiva, bem como nos seus documentos oficiais, o programa Mais Educação se caracteriza, especialmente, por trazer à tona a necessidade de ampliação das variáveis tempo e espaço no processo educacional, como uma tentativa de superação das desigualdades sociais (BRASIL, 2009a; MOLL, 2012; LECLERC, 2012).

Regulamentado pela Portaria interministerial $n^{\circ}$ 17/2007 e circunscrito, num primeiro plano, pelas demandas do setor empresarial, através do organismo "Todos pela educação" " e, num segundo plano, pelas ações do Plano de Desenvolvimento da Educação (PDE), este programa foi posteriormente modificado por outro instrumento normativo, o Decreto lei $\mathrm{n}^{\circ} 7.083 / 2010$. Atualmente, é possível afirmarmos que o programa Mais educação se situa em um espaço privilegiado nas ações desenvolvidas pelo Ministério da Educação (MEC), que procuram combater as desigualdades escolares por meio de programas com teor compensatório (SILVA, 2013).

Além disso, o impacto crescente dessa estratégia de indução nas escolas pode ser mensurado pelos dados apresentados no Educaceso: em 2010, os dados indicam um número ainda reduzido de alunos matriculados em programas que visavam o aumento do 
temo diário de permanência nas escolas, por meio da educação integral, apenas 414.889 (1,5\% do total); em 2011 os dados sugerem um aumento, já que 1.686 .407 (6,4\% do total) de estudantes estavam matriculados; em 2012, os dados também sugerem um aumento, 2.101.735 (8,2\% do total) (BRASIL, 2011; BRASIL, 2012; BRASIL, 2013). Para os próximos anos a tendência é de crescimento, visto que, as metas sobre essa matéria, contidas no novo Plano Nacional de Educação (Lei 13.005/2014), cuja projeção, no seu período de vigência (2014/2024), é de 50\% das escolas públicas oferecendo educação integral em tempo integral para 25\% das matriculas do ensina básico (BRASIL, 2014).

Assim posto, é possível sistematizarmos a perspectiva de educação integral do programa Mais Educação a partir de três aspectos, denominados nos seus documentos oficiais como "inovadores": a intersetorialidade; a diversificação das atividades escolares, por meio de oficinas realizadas no contraturno e a participação comunitária.

A intersetorialidade é definida como a responsabilização de Estados e municípios na implementação do programa, a tal estratégia indutora, afirmando ainda a necessidade de planejamento territorial de ações intersetoriais a partir da promoção de parcerias locais entre a escola a comunidade (BRASIL, 2009b). Esse aspecto tende a apresentar problemas decorrentes das "injunções político-administrativas locais" e "do ponto de vista operacional" que advém da tradição administrativa brasileira de funcionamento isolado dos diferentes setores que não estão objetivamente estruturados para atuar conjuntamente. Acreditamos que essa característica fortaleça práticas clientelísticas, isto é, a troca de favores, tanto no âmbito do executivo, entre os entes federados, como na ponta do processo, as escolas, em função da busca pelo acesso ao fundo público. Esse movimento é típico de um contexto de escassez de recursos no âmbito da educação (CAVALIERE, 2011; CURY, 2008).

Já a ideia de diversificação das atividades escolares, isto é, atividades esportivas, culturais, artísticas, ligadas à saúde, à assistência social, ao reforço escolar, entre outras, associadas ao currículo escolar por meio do projeto político-pedagógico (BRASIL, 2009c) não expressa necessariamente uma visão que corresponda a uma concepção democrática da educação que visa a universalização da oferta, tendo em vista os diferentes usos dessa ideia de diversificação ao longo da história educacional brasileira e as dificuldades de implementação desse conjunto de atividades em uma instituição "minimalista" e com uma estrutura de funcionamento duvidosa, como é a escola pública brasileira. Vale considerar também que a normatização do programa Mais Educação acerca dessa oferta de atividades diversificadas é no mínimo insegura, já que se ela se baseia no trabalho voluntário de "oficineiros", muitos com formação escolar, acadêmica e cultural questionáveis, que na primeira oportunidade de trabalho, com carteira assinada ou não, acabam deixando as oficinas do programa (CAVALIERE, 2011; SILVA, 2013).

$\mathrm{O}$ aspecto que enfatiza a participação comunitária nas atividades escolares, cara ao pensamento educacional liberal, conforme expressa Anísio Teixeira (2007), é utilizado como forma de desresponsabilização do Estado na oferta do direito à educação pelo programa Mais Educação. Nas escolas, ponta do "sistema", tenta-se estimular um cotidiano diferente do habitual, onde possam conviver diversos tipos de atividades pedagógicas (os "saberes escolares" e os "saberes comunitários"), desenvolvidas em espaços internos ou, preferencialmente, externos às instituições (BRASIL, 2009c). Como no Brasil a escola pública é a instituição responsável pela oferta desse direito às parcelas mais pobres da sociedade, esse processo acaba apresentando dificuldades em sua prática, já que essas parcelas são as que mais necessitam de investimentos, inclusive na própria estrutura física das escolas, e não de responsabilidades que, na maioria das vezes, possuem relação com a 
pouca estrutura de atendimento da escola pública (CAVALIERE, 2011).

Como podemos observar o programa Mais Educação possui uma perspectiva de educação integral que, acreditamos ser diferente daquilo produzido por Anísio Teixeira, não só pela questão do deslocamento histórico, isto é, contextos de produção diferentes, mas, sobretudo, em função dos objetivos apresentados no sentido de realização da educação integral. Nesse sentido, vejamos o que pensava Anísio sobre esse tema do campo da educação.

\subsection{O contexto de produção da Educação integral em Anísio Teixeira}

Desde o fim da primeira grande guerra, acontecimentos no Brasil sinalizavam a emergência de uma nova organização sociocultural. Devido à vinculação de fatores externos e internos ${ }^{5}$ o modelo econômico agrário-exportador entra em crise, dando lugar, mesmo que de modo gradual, ao modelo industrial com base na expansão das grandes cidades. A revolução de 1930, após um processo de sucessão presidencial fraudulento, renovou a classe dominante brasileira acrescentado ao aparelho do Estado frações de classe até então dele excluídas. É possível afirmarmos que essa modificação não se tratou de uma ruptura com as oligarquias provenientes da produção e exportação do café, mas sim de uma acomodação de outras forças produtivas oriundas de um incipiente processo de industrialização. Nesse período, especialmente devido a dois fatores, os avanços de revoluções socialistas pelo mundo e a demanda por escolarização numa sociedade que se industrializava, a questão social deixou de ser tratada pelas elites assentadas no Estado apenas como caso de polícia (CURY, 1984).

É Getúlio Vargas, nome de consenso entre as classes dominantes naquele contexto, na medida em que o cenário não apresentava somente uma relação entre "dominantes e dominados" - talvez a "correlação" pudesse ser vista como mais profunda: "setores agrários, operários urbanos, as camadas médias, o patronato, a igreja católica, as igrejas reformadas, as forças armadas se combinavam e se repeliam (...)" conforme as circunstâncias (BICCAS, FREITAS. p. 64) - que conduz o governo provisório (1930/ 34), promovendo uma série de mudanças no cenário brasileiro, inclusive na política educacional, que combinavam indicadores de desenvolvimento, com a manutenção das velhas estruturas de poder.

O serviço educacional prestado pelo Estado, naquele contexto, tinha relação com a formação de contingentes marginalizados nos grandes centros urbanos em expansão e isso pode ser explicado por um movimento singular que buscava reparar as desigualdades sociais, através da escola, mas que ao mesmo tempo produzia outras formas de desigualdade. Além do corte econômico, já bastante acentuado naquele momento, o próprio sistema educacional brasileiro restringia o prosseguimento da escolarização das classes populares.

Apesar do discurso favorável à ampliação das oportunidades escolares, por outro lado esse processo deslocava o olhar da desigualdade de condições existentes entre as classes sociais, para a constituição de uma uniformização educacional preocupada em resolver o déficit de crianças apensadas como alunos e recém ingressas em um esboço de sistema educacional. Isso modificava o cenário urbano, criava oportunidades de ingresso no âmbito escolar, mas incansavelmente produzia novos caminhos para desigualdade. "No bojo dessas relações sociais permaneceu fermentando uma sociedade em estado de contínuo estranhamento e alerta em relação ao cidadão pobre" (Id. p. 63).

Podemos observar, após a revolução de 1930, uma espécie de consenso em torno 
das demandas do campo social, notadamente no âmbito da esfera educacional: o Ministério da Educação e Saúde (1931), de Francisco Campos e as seguidas reformas protagonizadas, que notabilizaram o início da década de 1930 como "ponto de partida" da educação brasileira no caminho do capitalismo competitivo. Deixávamos de ser "liberais" e virávamos "produtores", dizia-nos o Ministro da Educação à época (CAMPOS, 1940).

Esses fatos denotam importância significativa para a análise aqui proposta. Afinal, mesmo com a realização de reformas - privilegiando o ensino secundário e superior -, a educação primária ainda seguia o curso da constituição de 1891 permanecendo sob a responsabilidade dos estados brasileiros e não do poder central. Segundo Moraes (1992), isso compunha a manutenção do poder local das oligarquias atribuindo a elas os rumos de tal segmento de ensino e, por consequência, da manutenção do poder local.

Com essa articulação, o debate sobre o ensino primário margeava os interesses de formação do Estado brasileiro, produzindo continuamente desigualdades de acesso ao ensino secundário intencionalmente elitista:

As medidas que redefiniram o ensino secundário e o ensino superior revelaram-se ações capazes de projetar socialmente, mas com uma nova figuração, o indivíduo das elites, ou melhor, os indivíduos das várias camadas de elites que se formavam no processo de consolidação da sociedade pós-escravidão no Brasil, especialmente no que tocava ao uso social da certificação escolar "enquanto" tal certificação proporcionava concretamente elementos de distinção entre pares. (FREITAS \& BICCAS, 2009, p. 70)

Dessa forma, o aumento da demanda de escolarização primária no início dos 1930 sem uma condição normativa e estrutural que a garantisse representava um modo de gestão das desigualdades sociais, afinal esse tratamento dado pelo Estado à escolarização dos mais pobres combinava uma expansão desordenada com a falta de qualidade dessa expansão: a marca da escola elitista permanecia.

Nessa conjuntura de "interesses diversos" no campo da educação, o nível secundário e o nível primário da escolarização assumiam a conta de uma cisão social complexa. Uma das saídas formuladas buscava concentrar nas mãos do Estado a difícil tarefa de centralizar as ações educacionais. Esse era o espírito dos muitos setores existentes convergentes na ideia de modernização do campo, porém divergentes na operacionalização desse processo.

Foi nesse contexto que o movimento da escola nova ${ }^{6}$ passou a reivindicar uma instituição escolar pública que atendesse de forma democrática, inclui-se ai a questão da laicidade, às necessidades de modernização da nação e isso incluiria a presença das classes populares na formação de nossas "elites intelectuais" 7 .

Ideais "escolanovistas" não ecoaram no vazio. A igreja católica reivindicava espaço de atuação no campo educacional, oferecendo significativa resistência a esses ideais considerados como subversivos, afinal, para eles, este movimento de "estadolatria" seria pernicioso, atentando contra a ordem através de um desregramento liberal propício a seduções do socialismo, como nos dizia Trystão de Athaíde na revista $\mathrm{A} \mathrm{Ordem}^{8}$.

O que caberia ao Estado, portanto, proporcionar as classes populares, somente uma escola para pobres ou reais possibilidades de disputa? A resposta dada pelos escolanovistas veio no "momento de compromisso" (CURY, 1984 p. 20) e em tom de manifesto: 


\begin{abstract}
Mas, do direito de cada indivíduo à sua educação integral, decorre logicamente para o estado que o reconhece e o proclama, o dever de considerar a educação, na variedade de seus gráos e manifestações como uma função social e eminentemente pública, que ele é chamado a realizar, com a cooperação de todas as instituições sociaes. A educação que é uma das funções de que a família se vem despojando em proveito da sociedade política, rompeu os quadros do communismo familial e dos grupos específicos (instituições privadas), para se incorporar definitivamente entre a funcções essenciaes e primordiaes do Estado. (MANIFESTO DOS PIONEIROS DA EDUCAÇÃO, 2001 p. 61 itálico nosso)
\end{abstract}

Para esse movimento caberia ao Estado estar à frente. $\mathrm{O}$ projeto de nação deveria possuir como parte emblemática uma educação pública que renovasse não só seus aspectos administrativos, mas suas necessidades pedagógicas, girando a discussão em torno da qualidade e não restrita, apenas, à expansão do número de frequentadores da vida escolar. Uma espécie de "espírito de qualidade" na educação iniciava um processo que veio a atravessar toda a nossa história, contribuindo para um quadro que materializava um dilema fundamentado na expansão e na qualidade da oferta do direito à educação.

Um sistema educacional com essa prerrogativa: uma alternativa de modernização que não possibilitasse o acesso à escolarização, apenas a poucas camadas da sociedade e a formação de uma elite intelectual conformada com o intelectualismo classista. Para isso, uma ambiência democrática era necessária à escola, articulando seus segmentos e produzindo uma autêntica reforma no sistema elitista da educação brasileira.

Fundamentado nesses princípios renovadores que no Distrito Federal, à época a cidade do Rio de Janeiro, cinco escolas foram incorporadas à iniciativa das "Escolas experimentais" idealizadas por Anísio Teixeira, um dos integrantes do Movimento da Escola Nova. Estas seriam "escolas-laboratórios" responsáveis por ensaiar "em condições tão livres e tão favoráveis quanto possível, algumas das técnicas da escola renovada.":

O Método de Projeto e a Escola-comunidade, na Escola Barbara Ottoni; o método de Dalton na Escola Manoel Bonfim; e o sistema de organização escolar chamado Platoon, nas Escolas Argentina, México e Estados Unidos. (TEIXEIRA, 1997 p. 203)

Por meio do decreto 3.763, de primeiro de fevereiro de 1932, Anísio Teixeira projetava outra concepção para a escola pública, mais ampla em seu serviço educacional, porém centralizada por um Estado indutor e realizador de suas funções pedagógicas.

Anísio buscava encerrar um debate que fragmentava o "que se aprende e o como se aprende, isto é, entre matéria e método.” (TEIXEIRA, 2006 p. 63). Dessa maneira, constatava-se o objeto na construção de uma sociedade democrática, onde a junção escola e democracia seria a unidade complexa, o ponto ativador de valores sociais invariavelmente solidários: "responsabilidades redobradas" para escola, experimentando uma composição metodológica que materializasse o pensamento de Anísio Teixeira sobre essa escola pública.

\title{
2.1 O caráter Democrático: "à margem dos Estados Unidos"
}

Na transição dos anos 1920 para os 1930, Clarice Nunes (2001) identifica a 
"primeira ruptura" de Anísio Teixeira. Uma travessia realizada no "deserto da fé", identificada na opção do educador pela dialética - "sem ser marxista". Um movimento no sentido contrário à sua formação católica, todavia plausível, tendo em vista o cenário urbano de desigualdades sociais do Rio de Janeiro, capital da primeira república, onde Anísio encontrava-se imerso.

Esse processo de ruptura teve início a partir de sua primeira viagem aos Estados Unidos (1924), sua primeira passagem pela América. Lá, Anísio pode observar a construção de um modelo de democracia organizado por uma "agência especial": a escola. Identificou que a função social da educação poderia estar disposta às necessidades de formação do mundo moderno, onde a participação social estivesse atrelada à constituição de um só caminho. Isso demarcava uma distinção entre o "treino" e a "verdadeira educação"; afinal, não adiantaria, somente, mecanizar o indivíduo a determinada atividade, mas sim fazê-lo compreender os sentidos de sua atividade social no interior da coletividade.

E justamente nessa compreensão da coletividade é que residia o "espírito" da democracia norte-americana:

(...) a tradição democrática não só provê ao preparo do indivíduo como tal, dando-lhe oportunidades econômicas e educativas, como ainda o prepara para a vida social (...) a democracia americana visa facilitar a necessária conciliação social, alargando os pontos de interesse comum, expandindo as possibilidades de contato e integrando, tanto quanto possível toda a estrutura social. O cidadão encontra assim, oportunidades para entender plenamente a multidão de interesses em conflito do país e de se ajustar ao seu plano complexo e vasto (TEIXEIRA, 2007a p. 25).

Para Anísio Teixeira, a construção da democracia poderia ser vista enquanto uma aspiração universal do Homem, um projeto coletivo, altruísta, "visto menos como um fato, do que como um ideal". Constatava a inexistência da democracia, enquanto uma visão estática e ressaltava que esta deveria estar atrelada ao conjunto das ações dos homens, "atitudes democráticas", em última análise. Contudo, esse processo deveria ser visto por uma vontade expressa na relação do homem americano com o seu meio, através do trabalho. Contradições eram identificadas, entretanto, mensuradas de acordo com o "velho espírito" pragmático presente na filosofia do pioneiro". Anísio acreditava que as problemáticas sociais próprias da modernidade seriam diluídas no processo democrático de construção da sociedade; afinal, não haveria nos Estados Unidos uma teoria democrática na contramão de práticas democráticas, e sim uma unidade, "um só corpo" (TEIXEIRA, 2007a).

Isso significa dizer que o preceito da sociedade moderna seria visto pela ótica da racionalidade científica, das consequências do desenvolvimento científico presentes no ato de experimentar. Anísio via esse movimento como possível pelo fato de, diferentemente da Europa, não haver na América uma "rigidez de quadros aristocráticos e hierárquicos" (Idem, p. 32). Segundo ele, essa marca possibilitaria o movimento oposto do ocorrido no velho mundo. Não haveria dispositivos sociais suficientes para "cristalizar" relações de classe, por isso a constituição da sociedade americana estava direcionada para construção de "uma nova casa", um bem comum talvez: "Enquanto a Europa parecia mais empenhada, segundo um recente escritor, nas razões de agir do que nos resultados da ação, a América lança no mundo uma filosofia inédita, essencialmente pragmática." (TEIXEIRA, 2007a p. 34 grifo nosso) 
Fundava-se nesse ponto a diferença substancial do processo democrático norteamericano, do "espírito" ao qual Anísio tanto se referia.

Democracia, assim, envolve um conceito de organização social em perpétuo fieri. Nada do que está estabelecido é definitivo. A sociedade vive em permanente reconstrução, em busca de formas dia a dia, mais amplas, mais eficazes, mais inteligentes. Tudo que identifica a atual ordem de coisas com rigidez, fixidez, imodificabilidade, nega o conceito de democracia. A solução presente não é mais do que uma tentativa, sujeita, permanentemente, á demonstração pragmática das suas consequências e resultados (TEIXEIRA, 2007a p. 40)

Anísio Teixeira observava o movimento educacional enquanto uma maneira de perpetuar as tensões entre o tradicional e o moderno, a desconfiança necessária para o desenvolvimento científico ${ }^{10}$. A veia pragmática da escola estaria na construção de reais situações de vida, onde os problemas dispostos para resolução estariam imersos na própria construção da democracia - escolas de experimentação, como gostava de chamar -, no entanto, Anísio não via toda essa construção em torno da democracia como enxuta de problemas. Considerava algumas limitações que, no âmbito da sociedade norte-americana, observava possibilidades de superação.

Partindo de uma concepção de democracia que se baseava na igualdade de oportunidades associada à meritocracia, Anísio Teixeira entendia ser possível combater os privilégios históricos presentes na sociedade brasileira por meio da educação e, em especial, por meio da instituição escolar. Para ele, a construção da democracia poderia ser vista como uma "conseqüência material e social do regime industrial moderno".

Toda a discussão deve basear-se no estrito reconhecimento dos fatos tais quais as novas forças objetivas de uma era industrial vieram determinar. Ora, malgrado, vicissitudes dos últimos cem anos de ocorrências sociais, é perfeitamente inegável o fato democrático. Nenhuma forma social, como nenhuma forma de governo se poderá erguer, em nenhuma parte do mundo civilizado, em que se evite uma participação mais ou menos larga do povo. (TEIXEIRA, 2007a p. 49)

Dessa maneira, a percepção das desigualdades poderia ser vista enquanto uma limitação "temporária", não como a supressão do regime democrático. Observava a migração de elementos das classes mais baixas para as mais altas como o resultado do espírito americano e de facilidades educativas. Por fim, entendia que esse processo caminharia para uma homogeneização das condições de acesso à competição social, o que possibilitaria um novo agrupamento, uma nova ordem. Definindo democracia como a cooperação entre os homens em torno de um bem comum, acreditava na educação escolarizada como força motriz de construção desse bem comum.

\subsection{A transformação da escola}

Inicia sua argumentação pela transformação da escola reforçando o entendimento da educação enquanto um processo inseparável da vida e, por esse motivo, acredita estar na compreensão da imaturidade o ponto chave para esse entendimento. Para ele, comparar a 
criança ao adulto seria incorrer no equívoco de encerrar as capacidades de desenvolvimento presentes nessa relação. Por isso, avançar nessa comparação estaria diretamente ligado ao sentimento de não apenas transmitir o conhecimento, mas sim construí-lo, experimentá-lo, a fim de novas formulações. Talvez seja possível considerar esse processo a partir de três conceitos: a experiência, a educação e a democracia. (CHAVES, 1999 p. 90)

Através desta tríade, Anísio procurava transformar a estrutura da escola, modificála substancialmente por meio de sua organização. Avesso à dualidade presente no sistema educacional brasileiro (escola das elites x escola das classes populares), encarava a construção de um sistema, stricto sensu, como desafio necessário ao desenvolvimento democrático. Acreditava como importante o diálogo entre os segmentos de ensino, modalidades, disciplinas, professores e alunos e não a falta de diálogo enquanto marca.

Tendo essas motivações em mente, propõe o ato de experimentar como mediação necessária na relação entre a educação e a democracia: não a considerava, portanto, como preparação para o futuro, mas como as experiências do presente que muito teriam utilidade. Nesse sentido, nos diz ser necessário perceber "a soma de interesses partilhados em comum" e a "cooperação com outros grupos distintos" de maneira que se explicitem as demandas e por consequência suas soluções. Experiência, portanto, seria o "(...) ato de fazer alguma coisa e sofrer dessa coisa certa reação. É um processo ativo e passivo. A experiência é educativa quando nos leva à reflexão, ao pensar" (TEIXEIRA, 2006 p. 60).

Por outro lado, se é através das experiências de vida que se constituem as novas relações entre educação e democracia, como pensar a ação escolar baseada numa escola dual, elitista como era o caso do Brasil? Anísio operava com a razão de que a escola deveria ser transformada:

Não seriam, pois, precisas outras razões que as da profunda modificação social por que vamos passando para justificar a alteração profunda da velha escola tradicional - preparatória e suplementar - na escola progressiva de educação integral (TEIXEIRA, 2007b p. 45 GRIFO NOSSO)

Construía o que chamava de uma nova postura psicológica em relação à escola, nos dizendo que esta deveria ser uma escola de vida e de experiência, uma escola onde os alunos fossem ativos, através de suas vontades e onde os professores compreendessem o sentido de que "(...) crescer é ganhar cada vez melhores e mais adequados meios de realizar a própria personalidade dentro do meio social onde se vive" (TEIXEIRA, 2007b p. 54).

A transformação deveria estar disposta para além da postura escolar em relação ao aluno, mas também para a proposição realizada sobre o que se considerava importante ensinar: os conteúdos e os programas escolares. Na contramão do "isolamento da vida" em que se colocam, estes conteúdos e programas deveriam ser integrados como elementos relacionais. Tendo a criança e suas necessidades, portanto, enquanto foco central, Anísio propunha a organização de experiências reais e socializadas e não somente a divisão em disciplinas:

O próprio estudo das matérias escolares nos vai levar, também, aos mesmos resultados. O mesmo problema visto de um ângulo diverso, ganha, se possível, maior clareza, e a solução aventada maior plausibilidade. (TEIXEIRA, 2007b p.72) 
Todo esse processo seria gradativo, "progressivo". Fundando escolas experimentais de acordo com a preparação de professores e dedicando parte do dia escolar para os experimentos, aos alunos caberiam, de maneira orientada, escolherem as atividades a fim de vivenciar novas ambiências, operando o sentimento de responsabilidade e de autonomia. Anísio trabalhava com essa ideia, mas também com algumas questões: "Que dizer, pois, de preparar a escola - a escola para todos - para, integrada na mesma finalidade, realizar com eficiência a nova educação do novo homem?" (TEIXEIRA, 2007b p.103).

\subsection{Uma Agenda Prática: O Rio de Janeiro}

Para essa pergunta, Anísio formulou “a poesia da ação". Uma reforma ampla no ensino do Distrito Federal, direcionado para todos os segmentos, em oposição à dualidade existente no sistema educacional brasileiro. Reuniu pela primeira vez no país a formação de cultura geral com o ensino técnico no secundário; introduziu a participação de estudantes nas gestões escolares, bibliotecas, rádio educativa; formação superior na Universidade do Distrito Federal para o professor primário - instituiu, assim, a educação enquanto área de investigação acadêmica. "Uma obra arduamente construída (...)" na cidade do Rio de Janeiro, "um sistema de ensino municipal que ia da escola primária à universidade (...)" (NUNES, 2001 p. 08). Um movimento que abria caminho para reinvenção da escola, mas principalmente a reinvenção do sistema educacional. Daí partia sua concepção.

No entanto, toda essa movimentação não passara inconteste naquele momento:

Nesse período conturbado, a administração de Anísio Teixeira sofre, como revela Paschoal Lemme, um de seus colaboradores, "todo o impacto dos acontecimentos contraditórios nele verificados". Suas iniciativas à frente da Secretaria tiveram não apenas um caráter de ampliação e consolidação do legado que recebera, em termos de modernização do sistema escolar, iniciado nas administrações anteriores, como a de Carneiro Leão (1922-1926) e, especialmente, a de Fernando de Azevedo (1927-1931), mas foram igualmente marcadas por características muito peculiares na consecução dos objetivos visados, o que provocou oposições radicais, mas também apoio de elementos respeitáveis do magistério carioca (LEMME, Apud FÁVERO, 2001 p. 03).

Isso viria reafirmar um cenário de intensa produção de desigualdade; afinal, ideologicamente existiam projetos em disputa e Anísio Teixeira, junto a seus colaboradores, ingressava nesse caminho sendo o Distrito Federal um palco privilegiado para seus intentos. Lá, reafirmou o seu comprometimento com o universalismo na educação. Um sistema integrado que fornecesse as respostas para as consequenciais da democratização da escola pública, afinal imperiosas eram na educação das massas a modificação dos métodos e por consequência as modificações na administração escolar.

No ensino elementar, por meio de um sistema de avaliação - oriundo dos Estados Unidos, mas adequado ao Distrito Federal - que à época levava em consideração o conhecimento da leitura e aritmético, se percebeu a ineficiência da escola pública. "Não basta haver escolas para os mais capazes: é dispensável que haja escolas para todos. Não 
basta haver escola para todos: é indispensável que todos aprendam". Ensinar no Distrito federal, portanto, estava ligado ao respeito às necessidades de aprendizado das diferentes classes sociais. Para tal, outras classificações, que não o sistema seriado, foram incorporadas (TEIXEIRA, 1997 p. 166).

Os programas escolares eram verificados, principalmente, através de "atividades ou projetos", tendo à escola a função de "ensinar a fazer". Separando no ensino elementar nos três primeiros anos as funções de leitura, escrita e aritmética, ficando a cargo dos dois últimos anos o desenvolvimento dessas técnicas através de atividades diversificadas: “(...) linguagem e matemática, ciências físicas e naturais e o de ciências sociais e ainda o de educação física e recreação, o de música e o de desenho e artes aplicadas." (TEIXEIRA, 1997 p. 182).

Nessa escola com possibilidades verdadeiramente populares, o processo de avaliação deveria estar disposto a verificar a diversidade presente em seus frequentadores, de modo a não constituir seleção, mas sim integração, flexível diante das necessidades apresentadas. E isso era possível, visto o "preparo vivo" iniciado nos anos anteriores na direção da educação no Distrito Federal por Carneiro Leão e Fernando Azevedo: uma nova “ideologia escolar" encontrava-se em curso. (TEIXEIRA, 1997).

No entanto, longe de ser um sistema homogêneo, tínhamos uma profunda desigualdade como marca, sendo a experimentação gradual uma maneira de proceder. Possuíamos escolas de todas as ordens, das mais sofisticadas até as mais rudimentares e a transformação desse cenário escolar - "instituições materiais e sociais (...) lentas, laboriosas e custosas" - não poderia ser visto da noite para o dia: "Temos, assim, programas desiguais para situações desiguais" (Id.).

À administração educacional caberia integrar-se em suas experimentações com o convívio comunitário, constituindo um movimento de aceitação das modifícações em curso. "Mais educação", portanto, era compreender as necessidades e articulá-las ao saber escolarizado, através da preparação de um sistema educacional.

Tanto a preparação de profissionais, por meio de um Instituto superior de educação, quanto à criação de superintendências para a diversidade dos programas escolares atendiam aos caminhos traçados para o que Anísio chamava de educação integral:

Os novos serviços de ensino instalados ou grandemente melhorados na escola pública, como os de música, desenho e artes industriais e educação física, recreação e jogos vieram por sua vez, reforçar o nosso empenho renovador e enriquecer a escola com elementos em profunda consonância com os melhores princípios e diretrizes da escola progressiva. (TEIXEIRA, 1997 p. 201).

Dessa forma, percebemos um conjunto de ações que apontavam para constituição de uma escola renovada, integral em suas ações e preocupada com a formação das classes populares. Essas eram as funções presentes nas escolas experimentais e em todo o complexo articulado no âmbito do sistema educacional pensado para o Rio de Janeiro.

Anísio Teixeira compreendia em sua atuação pública que era possível, através do "espírito democrático", modificar a cena de extrema desigualdade. Tivera essa chance na "capital cultural do país" e formulara uma concepção de educação integral baseada em três princípios articulados: a comunidade, a diversificação curricular e a eficiência do sistema educacional (FÁVERO, 2001).

\subsection{Sobre a perspectiva de educação integral em Anísio Teixeira em comparação com}

Revista HISTEDBR On-line, Campinas, $n^{\circ}$ 61, p. 202-218, mar2015 - ISSN: 1676-2584 213




\section{a perspectiva do programa Mais Educação.}

Anísio Teixeira atuava no campo educacional com uma visão predominantemente ampla. Para ele, este campo deveria ser compreendido, pela ótica da educação integral, como um sistema, isto é, um conjunto de ações articuladas que tivessem o objetivo de universalizar o acesso à educação por meio da escola. Possuía: i) uma visão ampliada das atividades escolares e não somente àquelas voltadas para a instrução, muito embora considerasse a importância dessas atividades em uma sociedade que se pretendesse moderna; ii) um entendimento igualmente ampliado de sistema, onde a integração entre níveis de ensino e modalidades da educação funcionasse de forma eficiente, isto é, as especificidades educacionais tratadas de modo permanente e não como soluções mirabolantes para os problemas decorrentes da ampliação das oportunidades educacionais; iii) e uma concepção de democracia fundada no liberalismo norte-americano, com fortes traços de associativismo, motivo pelo qual, muito provavelmente, afirmava ser fundamental a abertura da instituição escolar para a participação da sociedade, por meio das atividades com teor comunitário.

Já o programa Mais Educação, na atualidade, é implementado no campo da educação como uma visão especifica, na medida em que seu objetivo principal é apenas induzir, por meio de uma perspectiva de educação integral, estados e municípios a desenvolverem experiências nesse sentido. A problemática não é apenas de semântica, na medida em que essa indução: i) se caracteriza apenas por um aporte financeiro para as escolas direcionado para compra de materiais, alimentação e pagamento de auxílio para os "oficineiros" voluntários; ii) não se responsabiliza diretamente pelos desdobramentos administrativos, estruturais e pedagógicos nas escolas em que o programa é desenvolvido; iii) descaracteriza a educação como direito social, portanto, de todos, quando restringe o acesso às práticas a um grupo específico de alunos; iv) fortalece os laços clientelistas no âmbito das secretarias de educação e das escolas públicas por atribuir a elas uma lógica de "troca de favores" com a comunidade ao seu redor no que se refere a realização do programa.

Nesse sentido, comparando a perspectiva de educação integral presente no Programa Mais Educação com a perspectiva de Anísio Teixeira que apontamos anteriormente, podemos afirmar a existência de um antagonismo:

i) Porque no âmbito do programa que visa à educação integral, desenvolvido pelo MEC na atualidade, as atividades escolares são ampliadas por meio da introdução de "oficinas" (como banda, teatro, música, esporte, lazer, etc.) que devem estar vinculadas ao projeto político-pedagógico da escola, no entanto, essas "oficinas" não são destinadas ao conjunto da escola, mas somente para parte dos alunos. Isso simplifica a ação do programa e desloca sua atenção dentro da instituição escolar apenas para um grupo de alunos, cuja caracterização dada a eles destaca aspectos negativos, como o baixo rendimento escolar e o risco social. Ora, não são nas escolas públicas que também são processadas as desigualdades sociais, na medida em que são nelas que são escolarizadas as classes populares? Acreditamos que esse mecanismo do programa Mais Educação reforça essas desigualdades, justamente por não considerar a escola como um todo, como um "organismo vivo", conforme formulou Anísio Teixeira. Seria apenas uma parte da escola pública merecedora dessa atenção especial? Outro dado importante é a caracterização dos responsáveis por essas oficinas: o programa Mais Educação se baseia no trabalho voluntário, 
logo, os responsáveis pelas "oficinas" não são profissionais integrados à escola e recebem para desenvolverem seus trabalhos apenas uma ajuda de custo. Essas duas características quando comparadas à proposta de Anísio Teixeira, que pensava a diversificação das atividades escolares, mas por meio da criação de departamentos específicos, no âmbito do sistema educacional para cada atividade desenvolvida, podem ser caracterizadas como contrárias à universalização pretendida por ele, na medida em que não levam em consideração aspectos administrativos, estruturais e pedagógicos de um sistema educacional que se pretenda democrático. Existe uma fragilidade na afirmação de que o projeto político-pedagógico será o ponto de integração entre as atividades do currículo escolar e as oficinas desenvolvidas pelo programa Mais Educação, afinal, os responsáveis pelas oficinas não integram a instituição, como dissemos, e, mesmo que isso venha a ocorrer, como diferenciar o projeto político-pedagógico dos alunos que participam do programa daqueles alunos que dele não participam?

ii) Porque a perspectiva de educação integral em tempo integral contida no programa Mais Educação não possui o objetivo de integrar os níveis e modalidades educacionais, pelo contrário procura funcionar apenas como um fator de indução, para que municípios e estados da federação, dentro de suas competências em matéria de educação, possam desenvolver experiências pontuais voltadas para a educação integral. Na verdade, esse programa está longe de ser um fator de integração: se aproxima mais de uma perspectiva de diferenciação entre entes federados, haja vista que transfere para eles a responsabilidade de desenvolvimento de uma educação de qualidade, o que, convenhamos, estimula ainda mais as profundas diferenças sociais que existem entre os estados e municípios membros da federação.

iii) Porque quando comparamos aquilo que o programa Mais Educação sustenta como projeto democrático com o projeto de democracia de Anísio Teixeira, observamos um caminho bastante diferente. Anísio, não negava a necessidade de desenvolvimento de ações desiguais para situações desiguais, no entanto isso estava sempre de acordo com um modelo democracia que era idealizado para que todos pudessem ter acesso à educação e isso era materializado em ações estruturais no âmbito da escola pública. O programa Mais Educação, ao contrário disso, parece ignorar essa necessidade da educação brasileira, quando aponta para a focalização de suas ações sem uma preocupação com os aspectos estruturais de nosso fragilizado sistema educacional. Nesse sentido, podemos falar em um modelo de democracia que não é para todos, mas sim apenas para alguns.

iv) Porque as atividades com teor comunitário propostas por Anísio Teixeira, em hipótese alguma serviam como uma "muleta" para os problemas apresentados na oferta do direito à educação, reforçando assim o clientelismo. Essas atividades se sustentavam numa lógica de associativismo à americana, isto é, na ideia de que pragmaticamente os ensinamentos escolares deveriam estar colocados a serviço das necessidades imediatas daqueles que faziam uso da instituição escolar. Ao contrário disso, a perspectiva do programa Mais Educação, ao não colocar num primeiro plano as necessidades imediatas da escola pública que, aqui no Brasil, são iminentemente estruturais, visto o seu inacabado processo de universalização, não só negligencia isso, como também atribui à comunidade responsabilidades que não estão, pelo menos nesse momento, dentro de sua alçada. O que acaba por ocorrer é a lógica da troca de favores 
É através desses motivos, portanto, que consideramos contrária a perspectiva de educação integral presente no programa Mais Educação quando comparada à perspectiva formulada por Anísio Teixeira. O uso deste autor pelo programa do MEC, como já adiantamos, é uma mera ilustração - ou talvez uma "boa muleta" - que não possuí a preocupação de aprofundar o potencial heurístico presente em sua na obra.

Referências:

BICCAS, Maurilane de Souza; FREITAS, Marcos Cezar de. História Social da Educação no Brasil. São Paulo: Cortez, 2009

BRASIL. Educação integral: texto referência para o debate nacional. Brasília-DF: $\mathrm{MEC} / \mathrm{Secad}, 2009 \mathrm{a}$.

. Gestão intersetorial no território. Brasília-DF: MEC/Secad, 2009b.

Rede de saberes Mais Educação: pressupostos para projetos pedagógicos de educação Integral. Brasília-DF: MEC/Secad, 2009c.

Decreto 7.083 de 27 de janeiro de 2010. Dispõe sobre o Programa Mais Educação. Diário Oficial da União, Brasília, DF, 27 de janeiro de 2010. Disponível em: http://www.planalto.gov.br/ccivil_03/_ato2007-2010/2010/decreto/d7083.htm Acesso em nov. 2014.

INEP. Resumo técnico: Censo escolar 2010. Brasília: MEC/Inep, 2011. INEP. Resumo técnico: Censo escolar 2011. Brasília: MEC/Inep, 2012. INEP. Resumo técnico: Censo escolar 2012. Brasília: MEC/Inep, 2013. Planejando a Próxima Década. Conhecendo as Vinte Metas do Plano

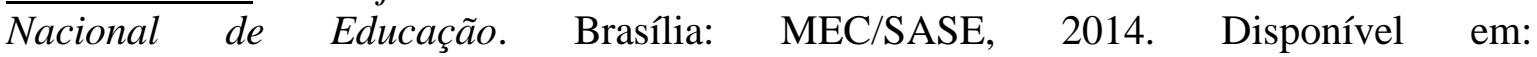
http://pne.mec.gov.br/images/pdf/pne_conhecendo_20_metas.pdf Acesso em nov. 2014.

CAMPOS, Francisco. Educação e Cultura. Rio de Janeiro: Livraria José Olimpio Editora, 1940.

CAVALIERE, Ana Maria Vilella. Anísio Teixeira e a educação integral. In Revista Paideia maio-ago. 2010, Vol. 20, No. 46, 249-259. ISSN 1982-4327.

Políticas especiais no ensino fundamental. In Políticas Públicas, Movimentos Sociais: desafios à Pós-graduação em Educação em suas múltiplas dimensões. FONTOURA, Helena Amaral da (org.). Rio de Janeiro: ANPEd Nacional, 2011. Disponível em: http://www.fe.ufrj.br/anpedinha2011/livro3.pdf Acesso em mar. 2014.

CHAVES, Mirian, Waidenfeld. A afinidade eletiva entre Anísio Teixeira e John Dewey. In Revista brasileira de educação. No 11 Mai/jun/jul/ago, 1999, p.86-99.

A Escola Nova na Cidade do Rio De Janeiro dos Anos 30: A Experiência da Escola Argentina. Caxambu - MG: 23 ${ }^{\text {a }}$ Reunião Anual ANPED, GT 02 História da Educação, 2000.

Educação Integral: Uma Proposta de Inovação Pedagógica na Administração Escolar de Anísio Teixeira no Rio de janeiro dos Anos 30. In COELHO, Ligia Martha C. C.; CAVALERE, Ana Maria Vilela. Educação Brasileira e $(m)$ Tempo Integral. Petrópolis - RJ: Editora Vozes, 2002.

COELHO, Ligia Martha C. C.. Historia(s) da educação Integral. In MAURÍCIO, Lucia Velloso (org): Em aberto: educação integral em tempo integral. v. 22, n. 80, p. 1-165, abr. 2009.

CURY, Carlos Roberto Jamil. Ideologia e Educação Brasileira: católicos e liberais. São 
Paulo: Cortez/Autores Associados, 1984.

. Políticas inclusivas e compensatórias na educação básica. São Paulo:

Cadernos de Pesquisa, v. 35, n. 124, p. 11-32, jan./abr. 2005. Disponível em: http://www.scielo.br/pdf/cp/v35n124/a0235124.pdf Acesso mar. 2014.

FÁVERO, M. de L. de A. Anísio Teixeira: construtor da educação pública. In: MONARCHA, C. (Org.). Anísio Teixeira: a obra de uma vida. Rio de Janeiro: DP\&A Editora, 2001.

LECLERC, Gesuína. Programa Mais Educação e Práticas de Educação Integral. . In MOLL, Jaqueline et al. Caminhos da educação integral no Brasil: direito a outros tempos e espaços educativos. Porto Alegre-RS: Penso, 2012.

MANIFESTO DOS PIONEIROS DA EDUCAÇÃO NOVA. In: Ghiraldelli Jr, Paulo. História da Educação. São Paulo: Cortez, 2001.

MARTINS, André Silva. "Todos pela educacao": o projeto educacional de empresários para o Brasil do seculo XXI. Caxambu-MG: Anais da Reuniao anual da ANPED, 2008.

MOLL, Jaqueline. A agenda da educação integral: compromissos para sua consolidação como política pública. In MOLL, Jaqueline et al. Caminhos da educação integral no Brasil: direito a outros tempos e espaços educativos. Porto Alegre-RS: Penso, 2012.

MORAES, Maria Marcondes. Educação e Política nos Anos 30: a Presença de Francisco Campos. In Revista Brasileira de Estudos Pedagógicos. Brasília: Inep, Vol 73, № 174, 1992.

NUNES, Clarice. Anísio Teixeira: a poesia da ação. In Revista brasileira de educação jan/fev/mar/abr, 2001 n $^{\circ} 16$ p.05-16.

RIBEIRO, Darcy. Ensaios Insólitos. Porto Alegre - RS: L\&PM Editores. 1979.

ROMANELLI, Otaíza de Oliveira. História da Educação No Brasil. Petrópolis-RJ: Ed. Vozes, 28ed. 2005.

SAVIANI, Demerval. Plano de desenvolvimento da educação: analise do projeto do MEC. In Educação e sociedade. Campinas - SP: vol. 28, n. 100 - Especial, p. 1231-1255, out. 2007.

SILVA, Bruno Adriano Rodrigues da. Interesses, dilemas e a implementação do programa Mais Educação no município de Maricá (RJ). Tese (Doutorado em Educação). Universidade Federal do Rio de Janeiro (UFRJ), 2013.

TEIXEIRA, Anísio. A educação escolar no Brasil. In FORACCHI, Marialice M.; PEREIRA, Luiz. Educação e sociedade (Leituras de sociologia da educação). São Paulo: Companhia Editora Nacional, 1979.

. Educação Para a Democracia: Introdução a Administração Educacional.

Rio de janeiro: Editora UFRJ, 1997.

Aspectos Americanos de Educação; anotações de Viagem aos Estados Unidos em 1927. Rio de janeiro: Editora UFRJ, 2006.

Em Marcha Para a democracia: à Margem dos Estados Unidos. Rio de janeiro: Editora UFRJ, 2007a.

Pequena Introdução à Filosofia da Educação: Escola Progressiva ou a Transformação da Escola. Rio de janeiro: Editora UFRJ, 2007b.

WEBER, Max. A ética Protestante e o Espírito do Capitalismo. São Paulo: Companhia das Letras, 2004) 
1 Universidade Federal de Lavras (UFLA) / Departamento de Educação Física (DEF)

2 Esse recorte se deve ao trabalho já realizado por Cavaliere (2010) que analisou três obras de Anísio Teixeira - Educação para a democracia (Teixeira, 1997), Educação não é privilégio (Teixeira, 1994) e Educação é um direito (Teixeira, 1996) - e concluiu que, apesar dele ter produzido "teórica e tecnicamente" uma concepção abrangente da educação, não se referia a isso como educação integral pela imprecisão e vinculação do termo a outras correntes ideológicas daquele contexto (década de 1930) como a Ação Integralista Brasileira (AIB) dirigida por Plínio Salgado e tidas por ele como conservadoras. Nessas obras que utilizaremos encontramos as referências sobre a perspectiva de Anísio Teixeira.

3 Segundo Cavaliere (2011) esse programa se aproxima da ideia das cidades educadoras que foi difundida teoricamente nos anos 1970 e institucionalizada a partir dos anos 1990, devido ao lançamento da Carta de princípios das Cidades Educadoras e criação de uma Associação de cidades de diferentes países (Associação internacional das cidades educadoras, 1994). Segundo a carta, em seu preâmbulo: "A cidade será educadora quando reconheça, exerça e desenvolva, para além das suas funções tradicionais (econômica, social, política e de prestação de serviços), uma função educadora, isto é, quando assuma uma intencionalidade e responsabilidade, cujo objectivo seja a formação, promoção e desenvolvimento de todos os seus habitantes, a começar pelas crianças e pelos jovens". Disponível em: http://w10.bcn.es/APPS/eduportal/pubFitxerAc.do?iddoc=84472. Acesso em Dez. 2012.

4 Organismo criado pelo setor empresarial (Fundação Itaú social, Grupo Gerdau, Instituto Camargo Correa, Fundação Bradesco, contando com a parceria da Rede Globo, Fundação Ayrton Senna e apoio da Fundação Victor Civita, Instituto Paulo Montenegro, entre outras empresas líderes, parceiras e apoiadoras), em 2006, com vistas a empreender um projeto educacional para o país (Martins, 2008). Segundo Saviani (2007) esse projeto do setor empresarial foi a base de sustentação para as ações do Plano de desenvolvimento da educação lançado ainda no governo Lula (PT) em 2007.

5 Segundo Cury (1984): "A diminuição dos vínculos da dependência externa, motivados pela primeira grande guerra, obriga os países periféricos a uma maior produtividade na área de industrialização de bens de consumo leve. As exigências crescentes do mercado interno, a elevação da produção cafeeira, as insatisfações regionais com o sistema de poder vigente determinam novas formas de divisão social do trabalho e introduzem uma reorganização nas estruturas da sociedade. Daí as primeiras greves operárias nos anos que antecedem 1920, o início das rebeliões militares, as insatisfações das oligarquias rurais regionais, excluídas do poder. Podemos ainda citar a fundação do partido comunista, a semana de arte moderna, a reorganização da Igreja Católica e a criação da Associação Brasileira de Educação" (p. 6).

${ }^{6}$ Segundo Romanelli (2005): "Que é que caracterizava, precisamente, esse movimento? Para servir-nos das palavras de um de seus lideres, Fernando de Azevedo, diremos que 'nesse período crítico, profundamente conturbado, mas renovador e fecundo, que sucedera um longo período orgânico, de domínio da tradição e de ideia estabelecidas, a vida educacional e cultural do país caracterizou-se pela fragmentação do pensamento pedagógico, a princípio, numa dualidade de correntes e, depois numa pluralidade e confusão de doutrinas, que mal se encobriam sob a denominação genérica de "educação Nova" ou de "Escola Nova", suscetível de acepções muito diversas" (p. 130).

7 Quanto a este ponto, é importante distinguirmos as ideias presentes no movimento "escolanovista". De um lado, podemos considerar enquanto "elites intelectuais" a formação de grupos oriundos das classes desfavorecidas para o provimento da direção e dos caminhos que suas classes de origem deveriam seguir para o fortalecimento de um regime liberal, de caráter vanguardista. De outro lado, a formação era tida como necessária enquanto possibilidade de disputas no âmbito da sociedade. Elites nas mais diversas classes operando vias democráticas de disputas: reais condições eram preconizadas (Nunes, 1991).

8 Importante espaço de divulgação do ideário católico brasileiro difundido a partir de 1921. Vale ressaltar que tal periódico expressava majoritariamente ideias de intelectuais do eixo Rio / São Paulo, muito embora circulasse por todo território brasileiro.

9 Utilizamos a construção teórica de Max Weber (2007) sobre o "espírito" do capitalismo ou um modo de vida burguês. Nessa articulação, Weber propõe um exame das conexões que ajudam a constituir uma forma genérica de se conceber o estilo (ou a falta dele) de produção e acumulação de riquezas presentes na sociedade norte-americana na passagem do séc. XIX e XX.

10 Darcy Ribeiro (1979) afirma as suas impressões sobre "Mestre Anísio" dizendo, dentre tantas, que "a única coerência admissível num pensador" era a fidelidade à busca da verdade. "Com efeito, o único meio de ser fiel à verdade é não ter compromisso com ideia nenhuma. As ideias são vestimentas provisórias de uma verdade sempre inatingível" (p. 131)

Recebido: abril-14 Aprovado: janeiro-15 